\title{
'Why, why did you have me treated?': the psychotic experience in a literary narrative
}

\author{
A A Kaptein, ${ }^{1}$ J J E Koopman, ${ }^{1}$ J A Weinman, ${ }^{2}$ M J Gosselink ${ }^{3}$
}

${ }^{1}$ Department of Medical Psychology, Leiden University Medical Centre (LUMC), Leiden, The Netherlands

${ }^{2}$ Health Psychology, Institute of Psychiatry, King's College

2 London, London, UK ${ }^{3}$ Department of Psychiatry, Leiden University Medical Centre (LUMC), Leiden, The Netherlands

Correspondence to Professor A A Kaptein, Department of Medical Psychology, Leiden University Medical Centre (LUMC), PO Box 9600, Post zone J9R, 2300 RC Leiden, The Netherlands; a.a.kaptein@lumc.n

Accepted 10 June 2011

\section{ABSTRACT}

In this paper, the authors suggest an approach that may be helpful in teaching medical humanities to medical students. In the context of an honours class on medicine and literature, students (1) read a novel on an illness, (2) interviewed a patient with the medical condition described in the novel and (3) wrote an essay on the biomedical, narrative and literary aspects of these sources of information. The authors compared the story of Chekhov's literary protagonist Kovrin in The Black Monk with the personal story of patient $H_{\text {., who was }}$ diagnosed with schizophrenia. The narratives of the two patients were compared, based on Chekhov's literary narrative and the narrative of the patient. Both patients appeared to somehow regret losing their symptoms, following various psychiatric treatments. Both narratives show the ambivalence between the gain and loss that adequate psychiatric treatment may bring. Studying novels and other literary sources may help in understanding the story of the patient better, with associated improvements in various aspects of medical outcome. Reading literary fiction may help to increase an understanding of patients' emotions, experiences, cognitions and perspectives. It may also reduce the emotional distance between the self and the patient. The educational approach that was explored in the authors' honours class may be helpful to others when developing methods for teaching medical humanities to (medical) students.

\section{INTRODUCTION}

Almost any current issue of a major medical journal reflects the dominance of biomedical views on human health and illness, and its medical management. ${ }^{1} 2$ Papers on brain chemistry, on schizophrenia as 'a glutamate disorder' or on 'aberrant brain activation during a working memory task in psychotic major depression' are just a few examples of this biomedical dominance. ${ }^{34}$ A recent editorial in $J A M A$ even maintained that empathy in medicine has a neurobiological basis, which made the authors suggest-interestingly-"that empathy can also be up-regulated through education. Medical educators can teach students about the neurobiological correlates of empathy ... advancing physician empathy with deliberate, neurobiologically informed training and research may be a helpful approach to enhance the professionalism and compassion that are the hallmark of medicine' (p. 1605). ${ }^{5}$ In the related editorial 'Wisdom-a neuroscience perspective', the authors maintain that 'developing biological means to enhance the elements of brain functioning that are critical to wisdom may be years away but is potentially achievable' (p. 1603). ${ }^{6}$ Whether this shows our wisdom or lack of it, we decided not to wait for 'the development of biological means', but embarked on trying to contribute to the literature on exploring illness from a medical humanities point of view.

\section{THE CONTEXT}

The eight medical schools in The Netherlands admit collectively some 3000 first-year medical students annually. In a document that defines the objectives of the four-year curriculum, inspired by the CanMEDS framework, some attention is given to 'medical humanities' albeit to a very modest degree (eg, '... the physician is able to gather information about a disease, but also about a patient's beliefs, concerns, expectations and illness experience ...', and '... to apply knowledge of the clinical, socio-behavioural, and fundamental biomedical sciences relevant to the physician's specialty' (pp. 65-6). ${ }^{7}$ Departments of medical psychology, public health, general practice, sexual medicine, psychiatry or medical humanities teach medical students about behavioural and social aspects in health and illness. Many medical students express their lack of interest in or even pure disgust about anything 'non-medical' in their curriculum. Various attempts have been described where staff (medical and behavioural) of medical schools aimed to stimulate a biopsychosocial approach to health and illness and to provide medical care in that context to ill persons.

Although it has been argued that in time all aspects of human life will be explained biologically, in the formulation of the psychiatric diagnosis and therapy, the evaluation of the patients' personal experience is a matter of course. ${ }^{8}$ This is particularly true for psychotic patients, where concern for the nature and quality of the patients' personal experiences is of major clinical importance. Recent research has identified the importance of understanding patients' perceptions of their condition and its treatment in those with both physical ${ }^{9}$ and mental health problems. ${ }^{10}$ Moreover, this focus should form the core of a good doctor-patient relationship in which the doctor has empathic skills, such as the ability to appreciate the patients' emotions and cognitions. Empathy and an appreciation of the patients' own perception of their illness and treatment have been shown to improve patient adherence, clinical outcome and patients' as well as doctor's satisfaction. ${ }^{11}$ However, it may sometimes be difficult to understand the personal experiences, cognitions, emotions and perspectives of the psychotic patient. ${ }^{10}$ Thus, to gain more insight into the subjective aspects of a disease, 
reading literary fiction may be of value. In contrast to scientific sources, many literary narratives focus on the subjective experience of a disease and reading them facilitates the development of empathic skills. ${ }^{13}$

Teaching medical students about medical humanities takes various forms. Lecturing and small discussion groups are the most common methods of teaching medical humanities or psychology/behavioural sciences. Various other approaches can be used in order to offer more attractive and original teaching methods. For example, preclinical medical students at Harvard Medical School were taught by staff from the Boston Museum of Fine Arts to observe systematically and in great detail the bodies of naked persons on selected paintings in that museum. After a number of sessions, the students reported their observations of real patients. Compared with the students in the control condition who did not participate in the observation training, the students in the 'experimental' group were much better in seeing diagnostic signs and in reporting what they saw in real patients. ${ }^{14}$ Crawford and Baker recently reviewed the area of the potential relevance of literature in teaching psychiatry, and concluded that studying psychiatry in literary texts 'can and should form an important part of a medical education' (p. 249), and offer a source of literature about psychiatry as well (http:// www.madnessandliterature.org/). ${ }^{13}$ Studying literature and examining its effects on students' empathy skills has been examined in a set of studies. A recent review of those studies is cautiously optimistic about the effects of those courses on medical students' interpersonal behaviour. ${ }^{15}$

In this context, an honours class in medicine and literature (MedLit) was given in 2010 at the Leiden University Medical Centre, where some 15 medical students and students in biomedical science participated. Figure 1 summarises one of the teaching approaches that were used. First, students selected a medical condition in which they were interested (left upper image). Second, they listened to the narrative of a patient with that particular condition (right upper image), preferably in the home of the patient in order to avoid a highly biomedical emphasis in the patient's story. Third, they identified and read a novel of the particular medical condition (left lower image) Their task was to integrate these three sources of information into a manuscript, where biomedical, biopsychosocial and literary themes converged. The students were encouraged to submit their essays to journals (medical, behavioural, social and/ or with a more literary emphasis), and examples of such papers were provided. ${ }^{16} 17$ One student has so far managed to have his paper published, ${ }^{18}$ while others are in the process of submitting and revising (and coping with rejections) their manuscripts. All manuscripts have been published in an edited book. ${ }^{19}$

\section{METHOD}

Consistent with the stages depicted in figure 1, three components make up the method for our paper.

1. The illness: Here it was decided to select 'psychosis' as the illness of study, given the student's (JJEK) interest in psychiatry.

2. The patient: Patient $\mathrm{H}$ is a 33-year-old single Caucasian man. From the age of 21 onward, he had been experiencing recurrent psychotic episodes, characterised by acoustic hallucinations, hypochondria and paranoid thoughts with delusions of reference. He was diagnosed with schizophrenia of the paranoid type (DSM-IV-TR). In 2010, he was referred by his psychiatrist to the Leiden University Medical Centre, with a persistent psychotic episode not responding to various pharmacological and psychotherapeutic interventions. In our hospital, he was treated successfully with electroconvulsive therapy (ECT) for his psychotic episode. During the ECT treatment, he also noted an improvement of his affective feelings and interpersonal skills. Despite the improvement, the negative symptoms still persisted, confirming the diagnosis of schizophrenia. Following ECT, haloperidol and lithium were successfully started as follow-up maintenance medication.

3. The novel: The story The Black Monk by Anton Chekhov was chosen as a source of literary image of the phenomenon 'psychosis'. ${ }^{20}$ Chekhov was a physician himself; he died at 
a very early age (48 years) because of tuberculosis. The Black Monk is a relatively short story (30 pages) that describes an episode of a few months in the life of Kovrin, a lecturer at a university in Russia. The protagonist is a young scholar who tries to write his $\mathrm{PhD}$ thesis. A state of 'being overworked and (with) his nerves upset' (p. 223) brings him to a villa in the countryside, where he stays with his stepfather and his daughter during the summer. He falls in love with the daughter and they marry. Symptoms of psychosis develop: he experiences visual and auditory hallucinations, manic bouts of activity, sleep disorder, depressed mood and frank episodes with hallucinations, where he believes 'he was chosen of God and a genius' (p. 252).

\section{RESULTS}

Some quotes from patient H's narrative illustrate the upper right image in figure 1. He has experienced his psychotic symptoms as uncontrollable and frightening:

I never felt safe, I kept on getting messages and I was cautious if 'they' were trying to inform me personally by certain television programmes. It's living in a nightmare.

He describes his psychotic periods as a traumatic major life event:

I was connected with a radio mast and able to communicate with it. During the night, they attacked me with all kinds of sounds to keep me awake, to deduce me; music to bring me in a world outside reality. I was thinking everything was about me, that they wanted to catch me, you know? I was haunted and they spied on me via the television.

Recently, he was treated effectively with ECT, followed by haloperidol and lithium.

The paranoia has gone, fortunately. I can think more clearly and concentrate better.

\section{A patient in the literature}

Chekhov's Kovrin is a productive and successful philosopher, working at the university. Following the advice of his doctor, he stays at his foster home for spring. He is adored as brilliant by his foster family and their neighbours. During his stay, Kovrin falls in love with Tanya, the daughter of his foster parents, and a marriage is soon arranged.

However, during his stay at his foster home, Kovrin experiences delusions of 'a monk dressed in black, with grey hair and black eyebrows, his arms crossed on his chest' (p. 230). The monk regularly pays him visits to converse with him. Kovrin realises that the monk is a hallucination and keeps his experiences secret, but this notion does not disturb him. Rather, the conversations with the monk stimulate him to a great joy and productivity. 'He sat down on the sofa and put his head in his hands, holding back the incomprehensible joy that filled his whole being, then he paced about again and sat down to work. But the thoughts he read in the book did not satisfy him. He wanted something gigantic, boundless, staggering' (p. 234). The monk explains the nature of his condition: "Yes. You are one of the few who are justly called the chosen of God. You serve the eternal truth. Your thoughts and intentions, your astonishing science and your whole life bear a divine, heavenly imprint, because they are devoted to the reasonable and the beautiful-that is, to what is eternal" (p. 237). The monk points out that having hallucinations is a sign of geniality and gift. "My friend, only the ordinary herd people are healthy and normal" (p. 238). These encouragements of the monk make Kovrin feel esteemed and chosen. 'He met the black monk once or twice a week, in the park or in the house, and had long talks with him, but that did not alarm him; on the contrary, it delighted him, because he was now firmly convinced that such visions came only to chosen, outstanding people who devoted themselves to the service of the idea' (p. 242). Kovrin's psychosis is discovered by Tanya when she finds him in conversation with the monk "“You're ill!" she began to sob, trembling all over' (p. 244).

Hereafter, Kovrin lets himself be treated by a doctor with bromide, warm baths and rest. From the treatment onward, Kovrin becomes irritable, changeable, quarrelsome and annoying. The beautiful garden he now experiences as gloomy. "The gloomy pines with their shaggy roots, which had seen him there last year so young, joyful and lively, now did not whisper but stood motionless, mute, as if they did not recognize him. And indeed his head was cropped, his long, beautiful hair was gone, his pace was sluggish, his face, compared to last year, had grown fuller and more pale' (p. 245). Kovrin regrets that he was treated. 'He clutched his head tightly with his hands and said in anguish: "Why, why did you have me treated? Bromides, inactivity, warm baths, supervision, fainthearted fear over every mouthful, every step-it will all finally drive me to idiocy. I was losing my mind, I had megalomania, but I was gay, lively, and even happy, I was interesting and original. Now I've become more solid and reasonable, but as a result I'm just like everybody: I'm a mediocrity, I'm bored with life ... Oh, how cruel you've been to me! I had hallucinations, but did that harm anybody? I ask you, did it harm anybody?"' (p. 246).

Our patient $\mathrm{H}$ reports similar responses to the more or less 'successful' medical management of his illness. Patient $\mathrm{H}$ is not satisfied with his treatment and he has difficulty adhering to his medication.

I'm not in the center of interest anymore. During my psychotic episodes, I noticed that girls liked me, many of them. I was attractive to them: they turned around passing by. They looked me straight in the eyes or smiled. That was good, that felt good. Now, I've lost that part of myself. Girls pass me by without a look. It feels like they lost interest in me. I feel as if invisible.

Kovrin is not able to enjoy his previous pleasures, such as wine, cigars and meals. His marriage with Tanya becomes hateful, resulting in a divorce. Also, Kovrin appears to encounter difficulties with his work, as a consequence of his lack of energy and inspiration. Years later, while thinking back to his time at Tanya's place, the monk appears to him again. 'Kovrin's breath was taken away, and his heart was wrung with sorrow, and a wonderful, sweet joy, such as he had long forgotten, trembled in his breast' (p. 251). Thinking back to the days at his foster home with the wonderful garden, his joyful scientific work and his happiness, Kovrin dies. During his last years, he regrets that his life has become mediocre and that he became reconciled to that.

Patient $\mathrm{H}$ tells similar observations:

Before my medical treatment, I found any woman attractive. Now, I look at fewer than $70 \%$ of them. It does bring some piece of mind, but I've lost part of my real self. I have the feeling that I am not longer noticed by women, no one is looking at me anymore.

\section{DISCUSSION}

Our study explored the subjective meaning of 'psychosis' in two patients: a patient from real life and a person in a literary source, a novel by Chekhov. In both patients, medical management resulted in the quite successful disappearance of major 
symptoms. At the same time, the patients themselves would not wholeheartedly agree with calling the management 'successful'. We believe that our paper broadly supports the arguments put forward in sources such as 'Making sense of madness'"1 or 'The meaning of madness', ${ }^{22}$ which maintain that exploring the narratives of patients diagnosed with 'schizophrenia' or 'psychosis' deserves our closest attention and that incorporating the patient's story into medical management may benefit the patient, the healthcare provider and society. In the larger context of medical humanities, our paper illustrates how reading novels and listening to the narrative of a patient (with any illness) may help in strengthening medical students' skills of approaching patients in a biopsychosocial perspective. Our focus here has not been that much on 'psychosis' specifically; we use this example from an honours class on medicine and literature as a teaching method.

We are aware of one other quite moving story in literature where a patient somehow experiences regrets when an illness has been successfully treated. Updike in 'From the journal of a leper' reports how a novel medical treatment (PUVA) appears to reduce his psoriasis to virtual absence. ${ }^{23}$ Given the detailed and beautifully written story of the major impact of psoriasis on his daily life, one, naively, would expect the patient to experience great relief after receiving medical management that resulted in the disappearance of his very visible symptoms. However, the author felt some regret for the very major changes that a life without psoriasis would imply. In a comment entitled 'The hidden delight of psoriasis', Meulenberg points out how sexuality and creativity are influenced by psoriasis, resulting in a reduction of both as its symptoms disappear. ${ }^{24}$

There is some literature on how studying literature by medical students or healthcare professionals may positively affect interpersonal skills. Shafer, Borkovi and Barr have developed a course 'Literature and Medical Interventions' and report qualitatively about the positive effects reported by the students. ${ }^{25}$ Shapiro and colleagues report similar findings after 'a spoonful of humanities ... that made the medicine go down' in a family medicine clerkship. ${ }^{26}$ Recently, similar findings were reported in medical training in oncology. ${ }^{27}$ Kumagai offers a conceptual framework for the use of illness narratives in medical education. ${ }^{28}$ These publications all point at two issues: (1) much more theoretical work is needed to put medical humanities, literature and medicine on a sound empirical footing and (2) there is growing evidence that introducing medical students to medical humanities can have positive effects on their insights and observational skills.

Our study, of course, has limitations. It is based on one novel and the narrative of one patient only. Further studies may focus on a larger sample of patients and a more structured interview schedule. At the same time, this is an exploratory study-with an additional purpose, that is, to examine whether the approach outlined in figure 1 is feasible as a method of teaching medical students about medical humanities. Given our experiences, we strongly believe that by combining the biomedical issues of an illness with biopsychosocial issues, medical students can learn about medical humanities as well as increase their understanding of the patients' condition.

Further research is needed to study the effects of a medical humanities course in medical education. Various outcome measures can be used: assessment of communication skills, patients' evaluations of physicians' behaviour and effects on 'concordance' (a concept that describes the extent to which doctor and patient have a shared understanding of the clinical problem). In our view, this research is very much needed in order to further strengthen the scientific basis of medical humanities. ${ }^{29} 30$ The further development of the clinical and research base of medical humanities may contribute to better clinicians. This would support the pleas in papers such as 'Re-visioning Flexner', and it may help to further develop 'The science of care' (Peabody). ${ }^{31-34}$

Funding This study was partially funded by the NIH.

\section{Competing interests None.}

Patient consent Obtained.

Provenance and peer review Not commissioned; externally peer reviewed.

\section{REFERENCES}

1. Insel TR. Rethinking schizophrenia. Nature 2010;468:187-93.

2. van Zuiden $\mathbf{M}$, Geuze $\mathrm{E}$, Willemen $\mathrm{HL}$, et al. Pre-existing high glucocorticoid receptor number predicting development of posttraumatic stress symptoms after military deployment. Am J Psychiatry 2011;168;89-96.

3. Coyle JT. Glutamate and schizophrenia: beyond the dopamine hypothesis. Cell Mol Neurobiol 2006;26:363-82.

4. Garrett A, Kelly R, Gomez R, et al. Aberrant brain activation during a working memory task in psychotic major depression. Am J Psychiatry 2011;168:173-82

5. Riess H. Empathy in medicine-a neurobiological perspective. JAMA 2010:304:1604-5.

6. Jeste VD, Harris JC. Wisdom-a neuroscience perspective. JAMA 2010;304:1602-3.

7. van Herwaarden CLA, Laan RFJM, Leunissen RRM, eds. Raamplan Artsopleiding 2009 [Masterplan Medical training]. Houten: Badoux, 2009.

8. Frank L. Mindfield: How Brain Science is Changing Our World. Oxford, UK: Oneworld Publications, 2009.

9. Horne R, Weinman J. Patients' beliefs about prescribed medicines and their role in adherence to treatment in chronic physical illness. J Psychosom Res 1999:47:555-67.

10. Kuipers E, Watson P, Onwumere J, et al. Discrepant illness perceptions, affect and expressed emotion in people with psychosis and their carers. Soc Psychiatry Psychiatr Epidemiol 2007:42:277-83.

11. McCabe R, Saidi M, Priebe S. Patient-reported outcomes in schizophrenia. $\mathrm{Br} \mathrm{J}$ Psychiatry 2007:191(Suppl 50):S21-8.

12. Jones $\mathbf{A H}$. Literature and medicine: Narratives of mental illness. Lancet 1997;350:359-61.

13. Crawford $\mathbf{P}$, Baker C. Literature and madness: Fiction for students and professionals. J Med Humanit 2009;30:237-51.

14. Naghshineh S, Hafler JP, Miller AR, et al. Formal art observation training improves medical students' visual diagnostic skills. J Gen Intern Med 2008:23:991-7.

15. State of the Field Committee. Arts in healthcare 2009. Washington DC: Society for the Arts in Healthcare, 2009

16. Kaptein AA, Lyons AL. Cancer ward: patient perceptions in oncology. J Health Psychol 2010;15:848-57.

17. Kaptein AA, Lyons AL. The doctor, the breath, and Thomas Bernhard: using novels in health psychology. J Health Psychol 2009;14:161-70.

18. Das T, Kaptein AA, Haan J. The turbid crystal ball: Life plans affected by multiple sclerosis. Literature and patient compared. Int MS J 2011:17:86-9.

19. Kaptein AA, ed. Medicine \& Literature Honours Class 2010 LUMC. Zierikzee: De Woordenwinkel, 2010

20. Chekhov A. The black monk. In: Stories (Translated by $R$ Pevear and L Volokhosky). New York: Bantam Books, 2000:223-52.

21. Geekie J, Read J. Making Sense of Madness: Contesting the Meaning of Schizophrenia. London: Routledge, 2009.

22. Burton N. The Meaning of Madness. Oxford: Acheron Press, 2009

23. Updike J. From the journal of a leper. Am J Dermatopathol 1982;4:137-42.

24. Meulenberg F. The hidden delight of psoriasis. BMJ 1997;315:1709-11.

25. Shafer A, Borkovi T, Barr J. Literature and medical interventions: an experiential course for undergraduates. Fam Med 2005:37:469-71.

26. Shapiro J, Duke A, Boker J, et al. Just a spoonful of humanities makes the medicine go down: introducing literature into a family medicine clerkship. Med Educ 2005:39:605-12

27. Khorana AA, Shayne M, Korones DN. Can literature enhance oncology training? A pilot humanities curriculum. J Clin Oncol 2011;29:468-71.

28. Kumagai AK. A conceptual framework for the use of illness narratives in medical education. Acad Med 2008;83:653-8.

29. Ousager $\mathbf{J}$, Johannessen $\mathrm{H}$. Humanities in undergraduate medical education: a literature review. Acad Med 2010:85:988-98.

30. Perry M, Maffulli N, Wilson S, et al. The effectiveness of arts-based interventions in medical education: a literature review. Med Educ 2011:45:141-8.

31. Doukas DJ, McCullough LB, Wear S. Re-visioning Flexner: educating physicians to be clinical scientists and humanists. Am J Med 2010;123:1155-6.

32. Greenhalgh T. Chronic illness: beyond the expert patient. BMJ 2009:338:629-31.

33. Peabody FW. The care of the patient. JAMA 1927;88:877-82 [see also Harris JC. Toward a restorative medicine-the science of caring. JAMA 2009:301:1710-2]

34. Oyebode F, ed. Mindreadings - literature and psychiatry. London: RCPsych Publications, 2009. 